\title{
Mobile Gamification Applied to Employee Productivity in Companies: A Systematic Review
}

\author{
Miguel Angel Cardoso Miranda, Alfredo Daza Vergaray \\ Universidad Cesar Vallejo, Avenida Alfredo Mendiola, Lima, Perú
}

\begin{abstract}
The main goal of this article is to identify the use of gamified mobile applications and their impact on work productivity. We employ a systematic review of the literature to discover to what extent gamified mobile applications improve worker productivity within a company. The intent is to contribute to more profound understanding of learning contexts, methodologies, techniques and objectives with the application of mobile gamification. The literature emphasizes that mobile gamification can be used to enhance the learning process, improve performance and achieve worker objectives, especially in production and IT areas. To do this, an analysis is presented of the areas that use mobile gamification, the techniques used and the effects that are achieved with its application in companies. It seeks to close the knowledge gap by quantifying the gamification characteristics found in applications. Due to the paucity of studies on mobile gamification at work productivity, this work also points the way to new research.
\end{abstract}

Keywords - mobile gamification, employee productivity, enterprise, apps, workforce.

\section{Introduction}

The activities and routines that this current rhythm of work life has is increasingly similar to a game,

DOI: 10.18421/TEM104-50

https://doi.org/10.18421/TEM104-50

Corresponding author: Miguel Angel Cardoso Miranda,

Universidad Cesar Vallejo, Perú.

Email: mcardosom5@ucvvirtual.edu.pe

Received: 03 October 2021.

Revised: 05 November 2021.

Accepted: 12 November 2021.

Published: 26 November 2021.

(c) BY-NC-ND (C) 2021 Miguel Angel Cardoso Miranda \& Alfredo Daza Vergaray; published by UIKTEN. This work is licensed under the Creative Commons AttributionNonCommercial-NoDerivs 4.0 License.

The article is published with Open Access at www.temjournal.com because certain steps must be followed and levels must be overcome to reach the set goals.[1]

We have lived experiences that lead us to certain satisfactions with which our behaviour is affected: teamwork, assuming roles, improving performance, achieving goals, results, obtaining rewards, among others, which are characteristics that we also find in games. [2] Various studies on these ways of confronting life have defined these dynamics that are intended to enhance motivation or reinforce behaviour to solve problems, improve productivity, activate learning or achieve objectives, in gamification. [3]

Gamification has been applied in various fields in recent years with good results, such as education [4], banking [5], sports or psychology [6], where game elements are used to increase motivation, commitment and participant performance. The cultural and commercial success that has been exhibited with the application of these methods has attracted the attention of companies [7], leading to their use in organizations despite signifying a greater investment [8], because many employees use their mobile devices constantly [9] and employers are beginning to see in them a tool to align with their goals. [10]

Likewise, in mobile applications, gamification has been an important part of their design, when the objective has been a greater participation of users and interaction between them. [11] Taking it as part of the design methodologies to business environments since it can be adapted in the different areas where the thought process and game mechanics seek to involve workers to solve problems within organizations, as well as motivate loyalty among their users. [12]

There is an increasing trend in the use of mobile applications: app downloads have grown from 147 billion in 2016 to 218 billion in 2020 worldwide.[13] This makes mobile gamification a promising field that can help improve engagement and motivation in company workers. In fact, there are already some standardized business tools that achieve these goals, 
such as Bizfit [14], Centrical [15] or Quizizz for Work [16].

There have been other works of literary review on applied gamification in various areas [17], and those that have taken into account gamification in mobile applications [18], focusing on identifying the specific characteristics or attributes of the applications (functionality, ease of use, privacy and security, interactivity) that motivate user participation.[19] However, few studies have investigated the influence of mobile gamification in improving work productivity.

Taking into consideration the aforementioned issues, the focus of this document will be to analyse the application of mobile gamification in the labour productivity of companies. The motivation of this article is to find out which are the most relevant data sources for the mobile gamification research area applied to labour productivity. This work is also aimed at discovering who the main authors of the topic are, which are the most relevant articles, as well as the challenges and deficiencies that may exist in the explored field. This literature review is intended to reinforce the current theoretical framework, which can support future research related to mobile gamification in companies. For this, a systematic review is proposed that will include the literature of the periods from 2016 to 2021 .

This document is organized as follows: section 2 will present the methodology of the systematic literature review. In section 3, the respective analysis of the results will be presented according to the questions asked and section 4 will show information about the limitations and future research. Finally, section 5 presents the conclusions that have been raised in this review.

\section{Methodology}

In this systematic review we will use the guidelines established by Kitchenham and Charters [20], which consist of three important phases as shown in Figure 1 :

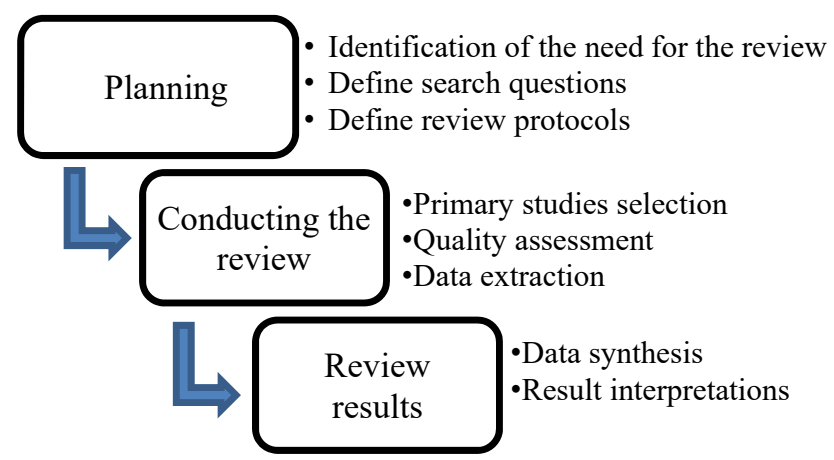

Figure 1. Systematic review process adapted from Kitchenham and Charters [20]
1. Planning the review: In this phase it is necessary to confirm the need to carry out the review, considering the research questions.

2. Carrying out the review: In this phase, the primary studies are selected, according to the inclusion and exclusion criteria.

3. Review results: In this phase, the statistics and analysis of the articles are displayed

\section{A. Planning the Review}

In order to have a clear idea about the scope of mobile gamification in companies, if these experiences have been positive or what mechanisms and techniques are the most appropriate to achieve positive effects, it is necessary to have the best evidence from the existing literature on the use of mobile gamification applied to labour productivity in companies. Thus, the systematic review planning process provides us with the best techniques for collecting and analysing primary studies.

The following repositories of indexed scientific articles were consulted: Springer Link, ScienceDirect, Scopus, IEEE Xplore, ACM and Wiley. A review protocol was also developed in which the search needs were identified in order to delimit the field of study about experiences, activities or theories of mobile gamification applied in labour productivity. The research questions for the information search are shown in Table 1:

Table 1. Literature search questions

\begin{tabular}{ccc}
\hline ID & Search Question & Motivation \\
\hline Q1 & $\begin{array}{c}\text { What studies are there } \\
\text { on mobile } \\
\text { gamification applied } \\
\text { in companies? }\end{array}$ & $\begin{array}{c}\text { Identify the areas involved } \\
\text { with the use of gamified } \\
\text { mobile applications within } \\
\text { companies. }\end{array}$ \\
\hline Q2 & $\begin{array}{c}\text { What gamification } \\
\text { techniques are used in } \\
\text { business mobile } \\
\text { applications? }\end{array}$ & $\begin{array}{c}\text { Reveal the various } \\
\text { gamification techniques } \\
\text { that are implemented in } \\
\text { mobile applications used by } \\
\text { companies. }\end{array}$ \\
\hline & $\begin{array}{c}\text { What effects does the } \\
\text { use of mobile } \\
\text { gamification have on } \\
\text { companies? }\end{array}$ & $\begin{array}{c}\text { Discover the main effects } \\
\text { detected related to the use } \\
\text { of gamified mobile } \\
\text { applications in companies. }\end{array}$ \\
\hline & &
\end{tabular}

\section{B. Conducting the Review}

\section{Initial search}

The search process began on May 20, 2021, with the first searches interconnecting terms 'gamification', 'work', 'mobile applications', 'productivity', 'gamification techniques', 'companies', in the following databases: ScienceDirect, IEEE Xplore, ACM, Scopus, Springer Link, InderScience, and Wiley. 
Subsequently, the search was expanded using Boolean AND and OR operators, in combination with terms 'mobile', 'gamification', 'employee', 'workplace', 'techniques', 'companies', 'productivity' and 'effects'.

These searches returned a very good number of results, many of them repetitive or of little use, but which gave a general idea of the spectrum of words that should be most effective in this search. In addition, they allowed to verify that, related to the subject of mobile gamification applied to labour productivity, no systematic review has been found.

As the results obtained in IEEE Xplore, InderScience and Scopus were scarce and did not appear to contribute any additional study or that it was included in the other databases, it was decided to withdraw them from the systematic review process.

\section{Systematic Search}

The systematic search continued in the databases SciencieDirect, ACM, SpringerLink, and Wiley, limiting the results to all publications made between 2016 and 2021.

From the initial experience, the combinations of words that produced the best results were found in the databases as shown in Table 2.

Table 2. Literature search chain

\begin{tabular}{cc}
\hline Question & Search string \\
\hline $\mathbf{Q 1}$ & $((($ MOBILE AND GAMIFICATION) AND \\
EMPLOYEE) AND PRODUCTIVITY) \\
\hline $\mathbf{Q 2}$ & $\left(\begin{array}{c}((\text { MOBILE AND GAMIFICATION) AND } \\
\text { TECHNIQUES) AND COMPANIES) }\end{array}\right.$ \\
\hline $\mathbf{Q 3}$ & $\begin{array}{c}((\text { MOBILE AND GAMIFICATION) AND } \\
\text { EFFECTS }) \text { AND COMPANIES })\end{array}$ \\
\hline
\end{tabular}

\section{Inclusion and Exclusion Criteria}

In Table 3., the criteria used to filter the papers are shown.

Table 3. Search criteria

\begin{tabular}{|c|c|}
\hline Inclusion criteria & Exclusion criteria \\
\hline $\begin{array}{c}\text { Publications related to } \\
\text { uamification in companies } \\
\text { using mobile applications }\end{array}$ & $\begin{array}{c}\text { Articles that do not meet } \\
\text { the inclusion criteria }\end{array}$ \\
\hline $\begin{array}{c}\text { Publications related to } \\
\text { mobile gamification } \\
\text { techniques in companies }\end{array}$ & $\begin{array}{c}\text { Review articles, theses, } \\
\text { newsletters, books, } \\
\text { manuals were excluded }\end{array}$ \\
\hline $\begin{array}{c}\text { Posts that mention gamified } \\
\text { mobile apps that improve } \\
\text { work productivity }\end{array}$ & $\begin{array}{c}\text { Articles focused on } \\
\text { mobile gamification } \\
\text { applied to education are } \\
\text { excluded }\end{array}$ \\
\hline
\end{tabular}

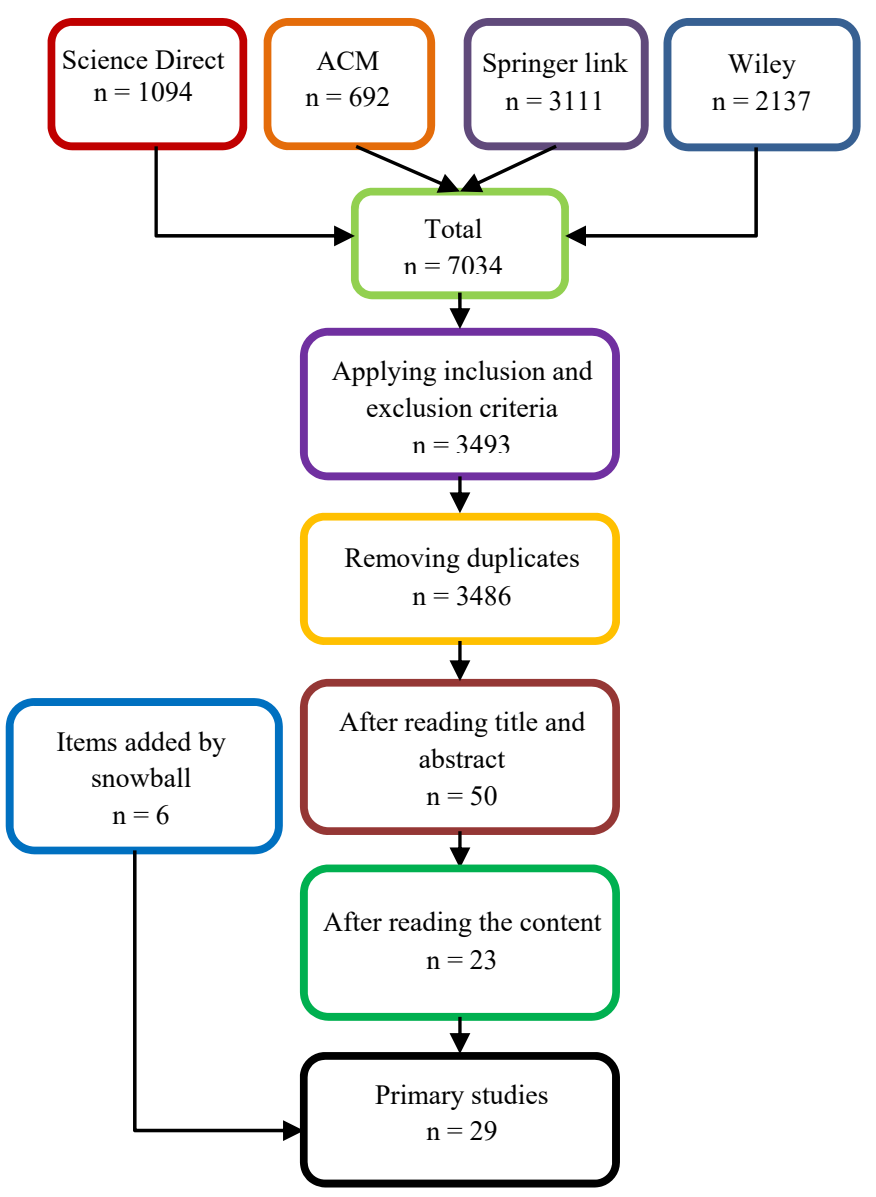

Figure 2. Article search process

\section{Additional filters:}

To continue with the selection of articles, the most refined filters will be applied in this way:

\section{First filter:}

Reading of title and abstract: It is submitted to reading and revision.

\section{Second filter:}

Full Text: Finally, we proceed to the complete reading and analysis of the studies that passed the first filter.

Once these last refined filters have been applied, the so-called snowball technique will be used, which consists of taking into account the references found in the filtered articles. [21], that can contribute more and / or better content to the systematic review and that have not been detected by the initial search chains.

Of the 7034 articles found, as shown in Figure 2., the inclusion and exclusion criteria were applied. Then, it was screened with more detailed filters annexing articles that appeared in the review process, obtaining a total of 29 primary studies.

\section{Review results}

The 29 studies found and detailed in Table 4. show a variety of content related to mobile gamification in business environments. 
Table 4. Results found

Ref.

Work gamification: Effects on

[22] enjoyment, productivity and the role of leadership

How a company's gamification strategy

[23] influences corporate learning: A study
based on gamified MSLP (Mobile social learning platform)

Augmented Reality and Gamification to

Increase Productivity and Job

[24] Satisfaction in the Warehouse of the Future

[25] A model for enhancing employees' lifelong learning intention online

[26] An exploration of world of Warcraft for the gamification of virtual organizations

[27] A framework for gamification in software engineering

A novel social gamified collaboration platform enriched with shop-floor data

[28] and feedback for the improvement of the productivity, safety and engagement in factories

[29] Human-centered performance management in manual assembly

Simulation-games for Learning

[30] Conducive Workplaces: A Case Study for Manual Assembly

[31] Game on: Engaging customers and employees through gamification

Leveraging learning with gamification:

[3] An experimental case study with bank managers

Gamification in e-Governance:

Development of an Online Gamified

[32] System to Enhance Government Entities Services Delivery and Promote Public's Awareness

Achiever or explorer?: gamifying the

[33] creation process of training data for machine learning

Architecting an extensible framework

[34] for Gamifying Software Engineering concepts

Gamification in mobile and workplace integrated microlearning

\section{Description}

The study investigates 114 employees who used the Habitica app, a mobile game for managing and tracking habits, finding that it improved enjoyment and productivity in those employees with leadership functions.

It addresses a theoretical framework to design mobile applications for gamified learning, taking as a reference a survey of 293 employees of a company in South Korea who used a Mobile Social Learning Platform (MSLP), demonstrating that a motivation for voluntary learning is achieved.

He suggests mobile gamification as a tool to increase motivation in workers, mainly in warehouse companies and distribution centres.

Examines the applicability of self-learning motivation through gamified online platforms. A survey of 255 workers in Thailand aged 25 to 54 years is taken as a basis, finding a positive contribution of mobile gamification in the self-learning of employees.

The study suggests taking the game World of WarCraft as a design model for gamified applications and thereby generating commitment and enjoyment that involve its members by supporting organizational strategies.

The study presents a framework with gamification support for software projects. A case study was carried out in a company for the areas of project management, requirements and tests, achieving a quality solution with an adequate effort in design and development.

It seeks to demonstrate that a gamified online access platform can motivate the level of commitment of workers. For this, the tool was tested for 3 months at the CERTH / CPERI plant, verifying a general improvement in positive mood together with commitment and satisfaction.

It seeks to demonstrate that gamified experiences through applications contribute to the operational performance and work motivation of plant workers. To do this, an MES application integrated in a business game simulation was used, within an assembly plant. Observations prove to be a source of motivation.

The study presents a new approach to the use of mobile gamification in industrial assembly environments, improving the learning processes of operators

It is discussed how gamification can help in the participation of clients and employees in a company. All this as a decision tool for managers.

Competitive game elements were shown to be effective as an aspect of instructional design, especially when a gamified digital feedback system was used as an evaluation tool in training bank managers.

Research using a gamified mobile app for employees of government organizations for training purposes.

Study that suggests gamifying several processes of manual creation of Machine Learning training data, to turn these tedious tasks into interesting ones.

Article that raises a software development framework where the design focuses on gamification and a structure adaptable to the requirements of the company.

The behavior of 175 employees with gamified mobile applications for learning processes was studied. An increase in the amount of information learned was not shown, but a shorter learning time 
[36] An Engaging Gamified Learning Mobile App for Microenterprises

The role of personal dexterity and incentive gamification to enhance employee learning experience and performance

GARUSO: a gamification approach for involving stakeholders outside organizational reach in requirements engineering

Enhancing motivation in workplace

[39] training with casual games: a twelve month field study of retail employees gamification

Gamification's impact on manufacturing: Enhancing job

[41] motivation, satisfaction and operational performance with smartphone-based gamified job design

[42] Gamification for software process improvement: a practical approach

Case study of the introduction of game design techniques in software development

Counterproductive effects of

[44] gamification: An analysis on the
example of the gamified task manager Habitica

Developing a gamified mobile

[45] application to encourage sustainable energy use in the office

Employee Profiles and Preferences

[46] towards IoT-enabled Gamification for Energy Conservation
[40] More than just a game: ethical issues in

It seeks to demonstrate that with a gamified mobile application, people can efficiently learn concepts and ideas that allow them to grow commercially.

It seeks to develop a concept of gamified systems. Questionnaires were made to 104 employees. The results show a positive effect on personal dexterity

Study that uses mobile gamification strategies to attract stakeholder participation in Requirements Engineering, achieving positive results.

Two study groups of employees in retail stores were used: one used a learning platform without gamification, and the other with gamification. The result showed that workers who had the gamified platform entered more frequently and provided better responses.

It seeks to develop a descriptive explanation of the ethical considerations associated with mobile gamification, focusing on aspects such as manipulation, privacy interruption, among others.

A case study is presented that tests a mobile application in an industrial plant. Operators are shown to achieve an improvement in job motivation, job satisfaction and operational performance.

It addresses the implementation of a framework integrating gamification for software development in order to motivate workers in the various processes. The results indicate that, although motivation did not increase, it did with job performance.

It proposes elements of game design in software development, especially in the Scrum process. The results obtained from the realization of a case study in a software development team of a company show that there was encouragement to the developers to carry out their daily tasks, although this result did not generate strong evidence of increased productivity.

A study is carried out based on surveys of users of the Habitica app, a gamified application that tracks tasks or habits. As a result, counterproductive effects are shown on users.

An application is put into use that tracks the energy use habits of employees, demonstrating that the system reduces electricity consumption by optimizing the use of resources.

The study proposes the use of gamified applications to motivate energy savings in their work centers. A survey was conducted with workers in three different locations: Spain, Italy and Switzerland. It was shown that those gamified apps that have progression levels and points motivate their workers to learn and become aware of the use of energy.

[47] Gamification of Enterprise Systems

The gamification as a tool to increase

[48] employee skills through interactives work instructions training

Presents a theoretical framework to implement gamification in business systems

It shares results of the adoption of gamification processes, which allowed, through the integration and involvement of work teams, the development of automated document control systems and selfevaluation processes in the production field, with favourable results.

Gamification in industrial shopfloor development of a method for

[49] classification and selection of suitable game elements in diverse production and logistics environments
It seeks to contribute new knowledge about the area of gamification in production and logistics from a conceptual point of view. Likewise, the gamification method developed allows the selection of specific game elements according to the company that takes it as a reference. 
In Table 5., it can be seen that the research articles also show an increase in interest in the topic of gamification in business applications.

Table 5. Number of articles by year of publication

\begin{tabular}{|c|c|l|}
\hline Year & Quantity & \multicolumn{1}{|c|}{ Related studies } \\
\hline 2016 & 4 & {$[30],[31],[34],[40]$} \\
\hline 2017 & 3 & {$[27],[32],[35]$} \\
\hline 2018 & 4 & {$[36],[41],[46],[48]$} \\
\hline 2019 & 5 & {$[38],[42],[43],[44],[47]$} \\
\hline 2020 & 7 & {$[22],[24],[26],[28],[33],[39],[45]$} \\
\hline 2021 & 6 & {$[3],[23],[25],[29],[37],[49]$} \\
\hline
\end{tabular}

\section{Analysis of the Results}

Based on the results found, the results will be analysed according to the questions posed at the beginning of the systematic review.

\section{Q1. What studies are there on mobile gamification applied in companies?}

The studies found and shown in Table 6 . give us a clearer vision of the areas in which mobile applications with gamification are currently being developed. These seek to collaborate with labour productivity.

Table 6. Studies on mobile gamification in companies

\begin{tabular}{ll}
\multicolumn{1}{c}{ Area } & \multicolumn{1}{c}{ Related studies } \\
\hline Storage & {$[24]$} \\
\hline Management & {$[31],[3],[38],[47]$} \\
\hline IT & {$[27],[33],[34],[42],[43]$} \\
\hline Production & {$[28],[29],[30],[41],[48],[49]$} \\
\hline Logistics & {$[49]$} \\
\hline HR $\quad[23],[25],[32],[35]$ \\
\hline \multicolumn{1}{c}{ Sales } & {$[36],[39]$} \\
\hline
\end{tabular}

Organizations take into account that employees are currently linked to a mobile device and make constant use of applications that help them relax and be entertained [50]. Thus, it is sought to take advantage and adapt the game towards activities that can normally be tedious or not very motivating [23]. For example, in the case of Human Resources areas, applications serve to improve the learning of workers [35] or guarantee the training of government employees. [32]

Employees in the production or manufacturing areas have a lot of repetitive work, which demands physical effort.[41] Mobile applications can help improve tasks [29] and improve work times. [48]

In the case of the Management area, mobile gamification allows managers and administrators to have a greater understanding of teamwork [3], assume leadership roles [31], value their team members for skills and use them intelligently to reach to the goals. [38]
For the information technology areas, software development can be more efficient, not only with agile methodologies [43], but also by incorporating the gamification of their processes [33]. This encourages a more active participation [34] and focused on having a quality product. [27]

To a lesser extent, mobile gamification is being used to train in sales techniques [39], or business management [36]. Similarly, in the studies found, the use in areas such as warehouses [24] and logistics is appreciated in order to improve the workers' mood. [49]

\section{Q2. What gamification techniques are used in business mobile applications?}

The techniques used in mobile gamification of business applications do not differ much from those already used in the predecessor gaming activities. Table 7. orders the techniques that were used in the articles reviewed.

Table 7. Studies on gamification techniques in mobile applications

\begin{tabular}{cl}
\hline Techniques & \multicolumn{1}{c}{ Related studies } \\
\hline \multirow{2}{*}{ Points } & {$[22],[25],[26],[28],[29],[30],[32],[35]$,} \\
& {$[36],[43],[44],[46]$} \\
\hline Badges & {$[22],[25],[27],[28],[29],[30],[32],[35]$,} \\
& {$[36],[43],[44],[46]$} \\
\hline Levels & {$[22],[26],[27],[32]$} \\
\hline Challenges & {$[3],[23],[36]$} \\
\hline Competence & {$[3],[23],[25],[26]$} \\
\hline Cooperation & {$[28],[45]$} \\
\hline Ranking & {$[3]$} \\
\hline Narrative & {$[45],[46]$} \\
\hline
\end{tabular}

According to the table shown, the point system is the most used in mobile gamification applications. This is because it is the simplest way to guarantee an interest in users. [29] Badges that assign the player an outstanding achievement are also considered as levels. [43]

Challenges [3] and competence [25] are mechanics that are used to test knowledge and skills of workers, which contributes to improving their levels of knowledge.

Narrative or cooperation are techniques that can be used in awareness activities, such as saving energy within the workplace. [45]

To a lesser extent the ranking or rating board is applied as a technique, because it can distract from the general objectives of the company. [3]

\section{Q3. What effects does the use of mobile gamification have on companies?}

In Table 8., positive effects are identified when using gamified mobile applications. 
Table 8. Studies on the effects of mobile gamification in companies

\begin{tabular}{cl}
\hline Effects edit & \multicolumn{1}{c}{ Related studies } \\
\hline Increase motivation & {$[22],[24],[29],[41],[42],[43]$} \\
\hline Improves mood & {$[28],[33],[37],[45],[46]$} \\
\hline Learning & {$[3],[23],[25],[30],[32],[35]$,} \\
improvement & {$[36],[39]$} \\
\hline Commitment & {$[26],[27],[28],[31],[32],[38]$,} \\
\hline Others & {$[48]$} \\
\hline
\end{tabular}

The main utility of gamification in the education sector is also found in companies [36], since it improves the learning of workers. [39] Thus, HR areas save resources by avoiding training workshops. [32]

Another positive effect found in the studies is the commitment of the users of gamified applications. [27] By mixing daily tasks with games [31], it achieves greater attention to the tasks in charge. [38]

Increasing motivation [22] or improving mood [28] are key in industrial work environments. This results in better performance because daily activities are done with a better will [45] and resources are saved. [46]

However, there will also be experiences where employees feel that these applications invade their privacy [44] or that they try to manage other aspects of their life. [40] For this reason, it is important to involve workers in the gamification designs of business applications. [34]

\section{Limitations and Future Researches}

Some limitations should be considered with respect to the literature review carried out. First, the size of the studies was not what we expected to cover. Additional studies with other types of research methods could provide additional information. In the second instance, the theoretical or motivational foundations of the collected articles were not discussed in this research, so this systematic review is limited with respect to the theoretical or motivational perspectives of the authors. Finally, application design is oriented at different levels of abstraction. This article focused on the level of game design features and the effects it causes on workers.

Therefore, we hope that these limitations can be transformed in future efforts and directions for new research. The business environment represents a diverse spectrum of ages, genders, and cultural backgrounds. Because of this, additional studies should be conducted on how to better design and implement mobile gamification to maximize skill development while addressing factors such as the psychological and motivational needs of a multigenerational workforce. In that sense, future studies should examine gender-based approaches in mobile gamification. Likewise, research should be related to the way in which mobile gamification addresses the needs and preferences of diverse cultures.

\section{Conclusion}

According to the analysis carried out on the findings of studies related to gamified mobile applications in work environments, we can conclude that they benefit productivity in companies, as long as their development is aligned with company policies and has been made a previous study of the fields that are wanted to be promoted within the workers.

It should be considered that the growth predictions of the development of gamified applications for companies, in the different global markets, and the prevalence of multinational corporations, present important research opportunities. Thus, according to our systematic review, there are areas that have not yet explored the use of this type of mobile applications, such as Service Desks, which would mean an improvement in the user experience through an increase in the productivity of service attentions. corresponding.

With this review of the literature, it is also verified that these applications must have directives to align objectives and key performance indicators in organizations or companies.

For the design and development of gamified applications aimed at improving work productivity, professionals must consider a variety of demographic and cultural factors, as standard business applications may not be the best option because they are not fully adapted to the organization. In addition, operational needs must be balanced with the needs of the worker. This contextualization is important for a better adoption within companies around these paradigm changes that the use of gamified applications means. 


\section{References}

[1]. Adhiatma, A., Sari, R. D., \& Fachrunnisa, O. (2021). The role of personal dexterity and incentive gamification to enhance employee learning experience and performance. Cognition, Technology \& Work, 113. https://doi.org/10.1007/S10111-021-00664-1

[2]. Alaghbari, S., Mitschick, A., Blichmann, G., Voigt, M., \& Dachselt, R. (2020, September). Achiever or explorer? gamifying the creation process of training data for machine learning. In Proceedings of the Conference on Mensch und Computer (pp. 173-181). https://doi.org/10.1145/3404983.3405519

[3]. Alloghani, M. A. M. A., Hussain, A., Al-Jumeily, D., Aljaaf, A. J., \& Mustafina, J. (2017, January). Gamification in e-governance: Development of an online gamified system to enhance government entities services delivery and promote public's awareness. In Proceedings of the 5th International Conference on Information and Education Technology (pp. 176-181). https://doi.org/10.1145/3029387.3029388

[4]. Clement, J.,(2018). Annual number of mobile app downloads worldwide 2018 | Statista. Retrieved from: https://www.statista.com/statistics/271644/worldwidefree-and-paid-mobile-app-store-downloads/ [accessed: 12 May 2021].

[5]. Baldwin, T. T., Kevin Ford, J., \& Blume, B. D. (2017). The state of transfer of training research: Moving toward more consumer-centric inquiry. Human Resource Development Quarterly, 28(1), 17-28. https://doi.org/10.1002/HRDQ.21278

[6]. Bizfit.,(2021). Enjoy fitting your workplace! Retrieved from: https://bizfit.app/ [accessed: 01 July 2021].

[7]. Cardador, M. T., Northcraft, G. B., \& Whicker, J. (2017). A theory of work gamification: Something old, something new, something borrowed, something cool?. Human Resource Management Review, 27(2), 353-365. https://doi.org/10.1016/J.HRMR.2016.09.014

[8]. Cechella, F., Abbad, G., \& Wagner, R. (2021). Leveraging learning with gamification: An experimental case study with bank managers. Computers in Human Behavior Reports, 3, 100044. https://doi.org/10.1016/J.CHBR.2020.100044

[9]. Cheng, V. W. S., Davenport, T., Johnson, D., Vella, K., Mitchell, J., \& Hickie, I. B. (2020). Naturalistic evaluation of a sport-themed mental health and wellbeing app aimed at men (MindMax), that incorporates applied video games and gamification. Internet interventions, 20, 100306. https://doi.org/10.1016/J.INVENT.2020.100306

[10]. Diefenbach, S., \& Müssig, A. (2019). Counterproductive effects of gamification: An analysis on the example of the gamified task manager Habitica. International Journal of Human-Computer Studies, 127, 190-210.

https://doi.org/10.1016/J.IJHCS.2018.09.004
[11]. Fang, J., Zhao, Z., Wen, C., \& Wang, R. (2017). Design and performance attributes driving mobile travel application engagement. International Journal of Information Management, 37(4), 269-283. https://doi.org/10.1016/J.IJINFOMGT.2017.03.003

[12]. Friedrich, J., Becker, M., Kramer, F., Wirth, M., \& Schneider, M. (2020). Incentive design and gamification for knowledge management. Journal of Business Research, 106, 341-352. https://doi.org/10.1016/J.JBUSRES.2019.02.009

[13]. Nah, F. F. H., Eschenbrenner, B., Claybaugh, C. C., \& Koob, P. B. (2019). Gamification of enterprise systems. Systems, 7(1), 13. https://doi.org/10.3390/systems 7010013

[14]. Gamification - Centrical., (2021). Retrieved from: https://centrical.com/platform/gamification/ [accessed: 19 June 2021].

[15]. García, F., Pedreira, O., Piattini, M., Cerdeira-Pena, A., \& Penabad, M. (2017). A framework for gamification in software engineering. Journal of Systems and Software, 132, 21-40. https://doi.org/10.1016/J.JSS.2017.06.021

[16]. Gerdenitsch, C., Sellitsch, D., Besser, M., Burger, S., Stegmann, C., Tscheligi, M., \& Kriglstein, S. (2020). Work gamification: Effects on enjoyment, productivity and the role of leadership. Electronic Commerce Research and Applications, 43, 100994. https://doi.org/10.1016/J.ELERAP.2020.100994

[17]. Göschlberger, B., \& Bruck, P. A. (2017, December). Gamification in mobile and workplace integrated microlearning. In Proceedings of the 19th international conference on information integration and web-based applications \& services (pp. 545-552). https://doi.org/10.1145/3151759.3151795

[18]. Herranz, E., Guzmán, J. G., de Amescua-Seco, A., \& Larrucea, X. (2019). Gamification for software process improvement: a practical approach. IET Software, 13(2), 112-121.

https://doi.org/10.1049/IET-SEN.2018.5120

[19]. Hofacker, C. F., De Ruyter, K., Lurie, N. H., Manchanda, P., \& Donaldson, J. (2016). Gamification and mobile marketing effectiveness. Journal of Interactive Marketing, 34, 25-36. https://doi.org/10.1016/J.INTMAR.2016.03.001

[20]. Huotari, K., \& Hamari, J. (2016). A definition for gamification: anchoring gamification in the service marketing literature. Electronic Markets, 1(27), 21-31. https://doi.org/10.1007/S12525-015-0212-Z

[21]. Hwang, J., \& Choi, L. (2020). Having fun while receiving rewards?: Exploration of gamification in loyalty programs for consumer loyalty. Journal of Business Research, 106, 365-376. https://doi.org/10.1016/J.JBUSRES.2019.01.031

[22]. Kapp, K. M., Valtchanov, D., \& Pastore, R. (2020). Enhancing motivation in workplace training with casual games: a twelve month field study of retail employees. Educational Technology Research and Development, 68(5), 2263-2284. https://doi.org/10.1007/S11423-020-09769-2

[23]. Kim, Seeun, \& Baek, T. H. (2018). Examining the antecedents and consequences of mobile app engagement. Telematics and Informatics, 35(1), 148158. https://doi.org/10.1016/J.TELE.2017.10.008 
[24]. Kim, S. (2021). How a company's gamification strategy influences corporate learning: A study based on gamified MSLP (Mobile social learning platform). Telematics and Informatics, 57, 101505. https://doi.org/10.1016/J.TELE.2020.101505

[25]. Kim, T. W., \& Werbach, K. (2016). More than just a game: ethical issues in gamification. Ethics and Information Technology, 18(2), 157-173. https://doi.org/10.1007/S10676-016-9401-5

[26]. Kitchenham B, Charters S., (2007). Guidelines for performing systematic literature reviews in software engineering. Version 2.3 University of keele (software engineering group, school of computer science and mathematics) and Durham. UK: Department of Conputer Science.

[27]. Koivisto, J., \& Hamari, J. (2019). The rise of motivational information systems: A review of gamification research. International Journal of Information Management, 45, 191-210. https://doi.org/10.1016/J.IJINFOMGT.2018.10.013

[28]. Kolpondinos, M. Z., \& Glinz, M. (2019). GARUSO: a gamification approach for involving stakeholders outside organizational reach in requirements engineering. Requirements Engineering 2019 25:2, 25(2), 185-212. https://doi.org/10.1007/S00766-019-00314-Z

[29]. Kotsopoulos, D., Bardaki, C., Lounis, S., \& Pramatari, K. (2018). Employee profiles and preferences towards IoT-enabled gamification for energy conservation. International Journal of Serious Games, 5(2), 65-85.

https://doi.org/10.17083/IJSG.V5I2.225

[30]. Lithoxoidou, E., Doumpoulakis, S., Tsakiris, A., Ziogou, C., Krinidis, S., Paliokas, I., ... \& Tzovaras, D. (2020). A novel social gamified collaboration platform enriched with shop-floor data and feedback for the improvement of the productivity, safety and engagement in factories. Computers \& Industrial Engineering, 139, 105691.

https://doi.org/10.1016/J.CIE.2019.02.005

[31]. Liu, M., Huang, Y., \& Zhang, D. (2018). Gamification's impact on manufacturing: Enhancing job motivation, satisfaction and operational performance with smartphone-based gamified job design. Human Factors and Ergonomics in Manufacturing \& Service Industries, 28(1), 38-51. https://doi.org/10.1002/HFM.20723

[32]. Müller, B. C., Reise, C., Duc, B. M., \& Seliger, G. (2016). Simulation-games for learning conducive workplaces: a case study for manual assembly. Procedia CIRP, 40, 353-358. https://doi.org/10.1016/J.PROCIR.2016.01.063

[33]. Murillo-Zamorano, L. R., Sánchez, J. Á. L., GodoyCaballero, A. L., \& Muñoz, C. B. (2021). Gamification and active learning in higher education: is it possible to match digital society, academia and students' interests?. International Journal of Educational Technology in Higher Education, 18(1), 1-27. https://doi.org/10.1186/S41239-021-00249-Y

[34]. Neto, P. S., Medeiros, D. B., Ibiapina, I., \& da Costa Castro, O. C. (2019). Case study of the introduction of game design techniques in software development. IET Software, 13(2), 129-143.
[35]. Ohlig, J., Hellebrandt, T., Poetters, P., Heine, I., Schmitt, R. H., \& Leyendecker, B. (2021). Humancentered performance management in manual assembly. Procedia CIRP, 97, 418-422. https://doi.org/10.1016/J.PROCIR.2020.05.261

[36]. Oppong-Tawiah, D., Webster, J., Staples, S., Cameron, A. F., de Guinea, A. O., \& Hung, T. Y. (2020). Developing a gamified mobile application to encourage sustainable energy use in the office. Journal of Business Research, 106, 388-405. https://doi.org/10.1016/J.JBUSRES.2018.10.051

[37]. Pereira, M., Oliveira, M., Vieira, A., Lima, R. M., \& Paes, L. (2018). The gamification as a tool to increase employee skills through interactives work instructions training. Procedia computer science, 138, 630-637. https://doi.org/10.1016/J.PROCS.2018.10.084

[38]. Ponis, S. T., Plakas, G., Agalianos, K., Aretoulaki, E., Gayialis, S. P., \& Andrianopoulos, A. (2020). Augmented Reality and Gamification to Increase Productivity and Job Satisfaction in the Warehouse of the Future. Procedia Manufacturing, 51, 1621-1628. https://doi.org/10.1016/J.PROMFG.2020.10.226

[39]. Quizizz for Work.,(2021). Engaging quizzes, polls, and presentations. Retrieved from: https://quizizz.com/forwork?ref=header tab [accessed: 01 July 2021].

[40]. Rapp, A. (2020). An exploration of world of Warcraft for the gamification of virtual organizations. Electronic Commerce Research and Applications, 42, 100985. https://doi.org/10.1016/j.elerap.2020.100985

[41]. Robson, K., Plangger, K., Kietzmann, J. H., McCarthy, I., \& Pitt, L. (2016). Game on: Engaging customers and employees through gamification. Business horizons, 59(1), 29-36. https://doi.org/10.1016/J.BUSHOR.2015.08.002

[42]. Rodrigues, L. F., Costa, C. J., \& Oliveira, A. (2016). Gamification: A framework for designing software in e-banking. Computers in Human behavior, 62, 620634. https://doi.org/10.1016/J.CHB.2016.04.035

[43]. Rubin, E., Dey, A., Mukherjee, D., \& Gibson, M. (2021). Managing the Universalization of Information Technology in organizations: The challenges and opportunities. Organizational Dynamics, 100857. https://doi.org/10.1016/J.ORGDYN.2021.100857

[44]. Samonte, M. J. C. (2018, April). An Engaging Gamified Learning Mobile App for Microenterprises. In Proceedings of the 2018 International Conference on Internet and e-Business (pp. 352-358). https://doi.org/10.1145/3230348.3230355

[45]. Sochor, R., Schenk, J., Fink, K., \& Berger, J. (2021). Gamification in industrial shopfloor-development of a method for classification and selection of suitable game elements in diverse production and logistics environments. Procedia CIRP, 100, 157-162. https://doi.org/10.1016/J.PROCIR.2021.05.024

[46]. Sripada, S. K., Reddy, Y. R., \& Khandelwal, S. (2016, February). Architecting an extensible framework for gamifying software engineering concepts. In Proceedings of the 9th India Software Engineering Conference (pp. 119-130). https://doi.org/10.1145/2856636.2856649 
TEM Journal. Volume 10, Issue 4, Pages 1869-1878, ISSN 2217-8309, DOI: 10.18421/TEM104-50, November 2021.

[47]. Tam, C., Santos, D. \& Oliveira, T.,(2020). Exploring the influential factors of continuance intention to use mobile Apps: Extending the expectation confirmation model. Inf Syst Front 22, 243-257 https://doi.org/10.1007/S10796-018-9864-5

[48]. Tarute, A., Nikou, S., \& Gatautis, R. (2017). Mobile application driven consumer engagement. Telematics and Informatics, 34(4), 145-156. https://doi.org/10.1016/J.TELE.2017.01.006
[49]. Thongmak, M. (2021). A model for enhancing employees' lifelong learning intention online. Learning and Motivation, 75, 101733. https://doi.org/10.1016/J.LMOT.2021.101733

[50]. Wohlin, C. (2014, May). Guidelines for snowballing in systematic literature studies and a replication in software engineering. In Proceedings of the 18th international conference on evaluation and assessment in software engineering (pp. 1-10). https://doi.org/10.1145/2601248.2601268 